\title{
Effect of Closure of Anterior Abdominal Wall Layers on Early Postoperative Findings at Cesarean Section: A Prospective Cross-sectional Study
}

\author{
Ersin Çintesun ${ }^{10}$ Ayşe Gül Kebapçılar ${ }^{1}$ (1) Mustafa Gazi Uçar ${ }^{1}$ (1) Setenay Arzu Yılmaz ${ }^{10}$

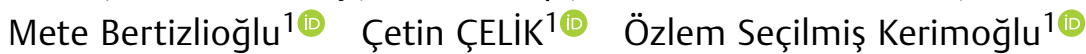

${ }^{1}$ Department of Obstetrics and Gynecology, Selçuk University Medicine Faculty, Selçuklu, Konya, Turkey Rev Bras Ginecol Obstet 2021;43(4):250-255.
Address for correspondence Ersin Çintesun, Selçuk Üniversitesi Tıp Fakültesi, Selçuklu/KONYA, Posta Kodu: 42075, Türkiye (e-mail: ersincintesun@gmail.com).

\begin{abstract}
\section{Keywords}

- analgesia

- cesarean

- intestinal motility

- parietal peritoneum

- rectus abdominis muscle

Objective To investigate the effect of closure types of the anterior abdominal wall layers in cesarean section (CS) surgery on early postoperative findings.

Methods The present study was designed as a prospective cross-sectional study and was conducted at a university hospital between October 2018 and February 2019. A total of 180 patients who underwent CS for various reasons were enrolled in the study. Each patient was randomly assigned to one of three groups: Both parietal peritoneum and rectus abdominis muscle left open (group 1), parietal peritoneum closure only (group 2), and closure of the parietal peritoneum and reapproximation of rectus muscle (group 3). All patients were compared in terms of postoperative pain scores (while lying down and during mobilization), analgesia requirement, and return of bowel motility.

Results The postoperative pain scores were similar at the $2^{\text {nd }}, 6^{\text {th }}, 12^{\text {th }}$, and $18^{\text {th }}$ hours while lying down. During mobilization, the postoperative pain scores at 6 and 12 hours were significantly higher in group 2 than in group 3. Diclofenac use was significantly higher in patients in group 1 than in those in group 2. Meperidine requirements were similar among the groups. There was no difference between the groups' first flatus and stool passage times.

Conclusion In the group with only parietal peritoneum closure, the pain scores at the $6^{\text {th }}$ and $12^{\text {th }}$ hours were higher. Rectus abdominis muscle reapproximations were found not to increase the pain score. The closure of the anterior abdominal wall had no effect on the return of bowel motility.
\end{abstract}

received

June 20, 2020

accepted

December 8, 2020

published online

March 30, 2021
DOI https://doi.org/

$10.1055 / \mathrm{s}-0041-1726057$

ISSN 0100-7203. (c) 2021. Federação Brasileira de Ginecologia e Obstetrícia. All rights reserved.

This is an open access article published by Thieme under the terms of the Creative Commons Attribution License, permitting unrestricted use, distribution, and reproduction so long as the original work is properly cited. (https://creativecommons.org/licenses/by/4.0/)

Thieme Revinter Publicações Ltda., Rua do Matoso 170, Rio de Janeiro, RJ, CEP 20270-135, Brazil 


\section{Introduction}

The attainment of safe delivery for both mother and baby via cesarean section (CS) is one of the important achievements of modern obstetrics. Cesarean section is one of the most frequently performed operations in the world, and its frequency is increasing. ${ }^{1,2}$ Cesarean section is defined as the delivery of the fetus by abdominal and uterine incision. As with every surgical procedure, there are many variations in carrying out CS, and the operation varies among surgeons. All stages of CS can be performed with different techniques. The effort to compare the different procedures of CS and to find a standard method of surgery has been ongoing for a long time. ${ }^{3-5}$

There are various studies comparing outcomes of closure and non-closure of the parietal and visceral peritoneum, and rectus muscle reapproximation and no approximation. In these studies, postoperative pain, need for analgesia, adhesion, infection, fever, endometritis, and duration of hospitalization were examined, ${ }^{5-9}$ and different results were obtained. Studies that compared postoperative pain and need for analgesia focused on the reapproximation of the rectus muscle without comparing parietal peritoneum closure or non-closure. ${ }^{8,9}$ In addition, there is no study investigating the relationship between the postoperative return of bowel motility and closure of the anterior abdominal wall layers.

In this study, we investigated the effect of closure types of the anterior abdominal wall layers on postoperative pain, need for analgesia, and postoperative return of bowel motility.

\section{Methods}

The present study was designed as a prospective crosssectional study between October 2018 and February 2019 in patients undergoing their CS at a university hospital. This study was conducted on patients who had standard CS surgical procedures in our clinic and who were eligible for the study. Anterior abdominal wall closure patterns vary from surgeon to surgeon in our clinic. This stage is implemented in three different ways. Group assignments were made by browsing the operation notes. Each patient was randomly assigned to one of these three groups:

Group 1: Both the parietal peritoneum and rectus abdominis muscle were left open;

Group 2: Parietal peritoneum closure only;

Group 3: Closure of the parietal peritoneum and reapproximation of rectus muscle.

The inclusion criteria were being at 37 or more weeks of gestation, not having systemic disease, having standard CS procedures under spinal anesthesia. Elective CS patients and patients in labor were included the study. The exclusion criteria included the following: patients with preterm births (less than 37 gestational weeks); administration of anesthesia besides general anesthesia; fetal distress; maternal hypertensive disorders; maternal systemic diseases; preeclampsia; premature rupture of membranes; chorioamnio- nitis; pregestational and gestational diabetes; placental invasion anomalies; coagulation disorders; multiple pregnancies; renal, liver, and gastrointestinal disease; history of $>3$ previous CS; presence of dense adhesions; and psychiatric disorders.

Approval from the institutional local ethics committee was obtained, and each patient provided a signed informed consent for their participation in the study. All staff members (nurses and investigators) were blinded to the study groups, and all postoperative procedures were made while remaining blinded. The health care provider who questioned the patient about pain after the operation and medicated the patient did not know which procedure was applied.

\section{Postoperative Patient Follow-up}

As a standard treatment in our clinic, we use intramuscular diclofenac for analgesia for the first 24 hours ( $1 \mathrm{~g}$ every $8 \mathrm{~h}$ ) and orally 3 times per day thereafter. In the case of patients who describe pain (visual analogue scale [VAS] $\geq 30$ ) in spite of the treatment with diclofenac, we administer narcotics as an analgesic instead of diclofenac. All patients receive preoperative prophylactic intravenous antibiotics (cefazolin $2 \mathrm{~g}$ ). Liquid food intake and mobilization of the patients are performed at the 6th postoperative hour. The nursing staff monitor and record maternal blood pressure, pulse activity, and urinary output hourly during the first 24 hours.

In the present study, postoperative pain was measured using a VAS $(0=$ no pain and $100=$ worst pain ever). All mothers completed the VAS score at the $2^{\text {nd }}, 6^{\text {th }}, 12^{\text {th }}$, and $18^{\text {th }}$ hours after surgery with the assistance of nursing staff. Pain scores were recorded at the $2^{\text {nd }}$ hour while lying down, and at other hours, pain scores were recorded both while the patient was lying down and during mobilization. The time to return of bowel function was recorded from the end of the surgery to the times of the first passage of flatus and stool. No medical or mechanical intervention was performed for passing flatus and stool. The patients were discharged at 48 hours postoperatively. No intervention was used for patients who did not pass stool within 48 hours.

\section{Surgical Technique}

Cesarean section is performed in our clinic as described below. All CSs are performed by the senior assistant. Nearly all surgeries are performed under spinal anesthesia. A standard technique is used in all procedures. All women have a Pfannenstiel-type transverse incision. The subcutaneous tissue layer is dissected using the fingers, and then a small transverse incision is made, medially, with a scalpel and extended laterally using scissors in the fascial layer. The rectus muscles are separated bluntly. The peritoneum is opened with the forefinger. A bladder flap is formed, and a low transverse incision is made in the uterus. The uterine incision is closed using a single-layer continuous locked suture with a Vicryl 1.0 suture (Ethicon, Johnson \& Johnson, Cincinnati, OH, USA). The abdominal cavity is cleaned from amniotic fluid and blood. The closure of the parietal peritoneum and rectus muscle in our clinic varies according to the preference and experience of the surgeon. The parietal 
Table 1 Comparison of demographic characteristics and physical conditions

\begin{tabular}{lllll}
\hline & $\begin{array}{l}\text { Group 1 } \\
\mathbf{N}=60\end{array}$ & $\begin{array}{l}\text { Group 2 } \\
\mathbf{N}=60\end{array}$ & $\begin{array}{l}\text { Group 3 } \\
\mathbf{N}=60\end{array}$ & $\begin{array}{l}\text { p-values } \\
\text { (among groups) }\end{array}$ \\
\hline Age $^{*}$ & $28 \pm 6.1$ & $30 \pm 5.7$ & $29 \pm 5.7$ & 0.495 \\
Gravidity $^{* *}$ & $2(1-6)$ & $2(1-6)$ & $2(1-8)$ & 0.380 \\
Parity** $^{*}$ & $1(0-4)$ & $1(0-4)$ & $1(0-5)$ & 0.782 \\
Weight (before Caesarean section) $^{*}$ & $78 \pm 13$ & $81 \pm 14$ & $77 \pm 13$ & 0.124 \\
Weight (before pregnancy) $^{* *}$ & $65(40-115)$ & $68(43-103)$ & $63(47-105)$ & 0.177 \\
Height $^{*}$ & $162.4 \pm 6.2$ & $162.4 \pm 5.8$ & $162.6 \pm 5.7$ & 0.982 \\
Weight gain during pregnancy $^{* *}$ & $10(2-20)$ & $11(3-28)$ & $11(2-21)$ & 0.124 \\
BMI (before pregnancy) $^{* *}$ & $24.8(18-40)$ & $26.4(16-38)$ & $23.4(18-38)$ & 0.108 \\
BMI (before birth) $^{* *}$ & $28.6(21-40)^{\mathrm{a}}$ & $30(18-40)^{\mathrm{a}, \mathrm{b}}$ & $28(20-42)^{\mathrm{b}}$ & 0.030 \\
\hline
\end{tabular}

${ }^{*}$ One-way analysis of variance $\left({ }^{*}\right)$ and Kruskal-Wallis $\left({ }^{* *}\right)$ variance analysis as appropriate.

Bold values represent $p<0.05$.

Data shown mean \pm SD and median (minimum-maximum).

${ }^{\text {a }} 1<0.05$ versus $\mathrm{P} 2$ (Kruskal-Wallis, Mann-Whitney U-test).

${ }^{b} \mathrm{P} 2<0.05$ versus P3 (Kruskal-Wallis, Mann- Whitney U-test).

peritoneum is closed using a continuous Vicryl 2.0 suture (Ethicon Johnson \& Johnson). The rectus muscles ere reapproximated using three loose vertical midline interrupted sutures with Vicryl 2.0 sutures (Ethicon Johnson \& Johnson). Sutures are placed about $1 \mathrm{~cm}$ from the edge of the incision and $1 \mathrm{~cm}$ apart, without excessive tension. Subcutaneous fat is closed when the tissue is thicker than $2 \mathrm{~cm}$. Skin is reapproximated using a continuous subcuticular suture with 2.0 polypropylene (Ethicon Johnson \& Johnson). All operative procedures are performed by the same surgeon. The day of CS is considered as day 0 .

\section{Statistical Analyses}

The G*Power 3.0.10 software (Franz Faul, Uni Kiel, Germany) was used for calculating the sample size. ${ }^{10}$ Sample size was calculated with an alpha of 0.05 , a power of 80 , and medium effect size (f) 0.25 . Given this calculation, the minimum required sample size was 53 patients in each group. One hundred and eighty patients were included in the study. Statistical analyses were performed using the IBM SPSS Statistics for Windows 21.0 software (IBM Corp.,
Armonk, NY, USA). Parametric continuous data were presented as means \pm standard deviation, nonparametric continuous data were presented as medians (min-max). Categorical variables were expressed as numbers (percentages). For statistical analysis, one-way analysis of variance (ANOVA), Kruskal-Wallis, Mann-Whitney U, and Pearson chi-squared tests were used, as appropriate; $p<0.05$ was considered significant.

\section{Results}

A total of 180 women who underwent CS for various reasons, including planned repeated cesarean delivery with up to maximum three previous CSs, were enrolled in the study. All patients were similar in groups with respect to age, weight, and body mass index (BMI).

Sixty women were allocated to each group. The most frequent indications for CS were as follows: elective repeat CS, malpresentation, and macrosomia. The demographic and physical conditions of the subgroups are summarized in table 1. Age, gravidity, parity, weight (before CS), weight

Table 2 Comparison of groups in terms of visual analog scale (VAS)

\begin{tabular}{lllll}
\hline & $\begin{array}{l}\text { Group } 1 \\
\mathbf{N}=60\end{array}$ & $\begin{array}{l}\text { Group } 2 \\
\mathbf{N}=60\end{array}$ & $\begin{array}{l}\text { Group 3 } \\
\mathbf{N}=60\end{array}$ & $\begin{array}{l}\text { p-values } \\
\text { (among groups) }\end{array}$ \\
\hline VAS 2nd hour & $60(10-100)$ & $70(10-100)$ & $60(10-95)$ & 0.077 \\
VAS 6th hour (lying down) & $30(0-90)$ & $30(0-70)$ & $27.5(0-80)$ & 0.203 \\
VAS 6th hour (mobilized) & $50(10-100)$ & $50(10-100)^{\mathrm{b}}$ & $40(10-90)^{\mathrm{b}}$ & 0.029 \\
VAS 12th hour (lying down) & $20(0-85)$ & $27.5(0-90)$ & $20(0-90)$ & 0.201 \\
VAS 12th hour (mobilized) & $40(5-90)$ & $40(5-100)^{\mathrm{b}}$ & $40(0-100)^{\mathrm{b}}$ & 0.022 \\
VAS 18th hour (lying down) & $10(0-40)$ & $20(0-50)$ & $20(0-50)$ & 0.157 \\
VAS 18th (mobilized) & $27.5(0-70)$ & $30(10-90)$ & $30(0-70)$ & 0.188 \\
\hline
\end{tabular}

Kruskal-Wallis (Mann-Whitney U-test) variance analysis as appropriate.

Bold values represent $p<0.05$.

Data shown median (minimum-maximum).

${ }^{\mathrm{b}} \mathrm{P} 2<0.05$ versus $\mathrm{P} 3$. 

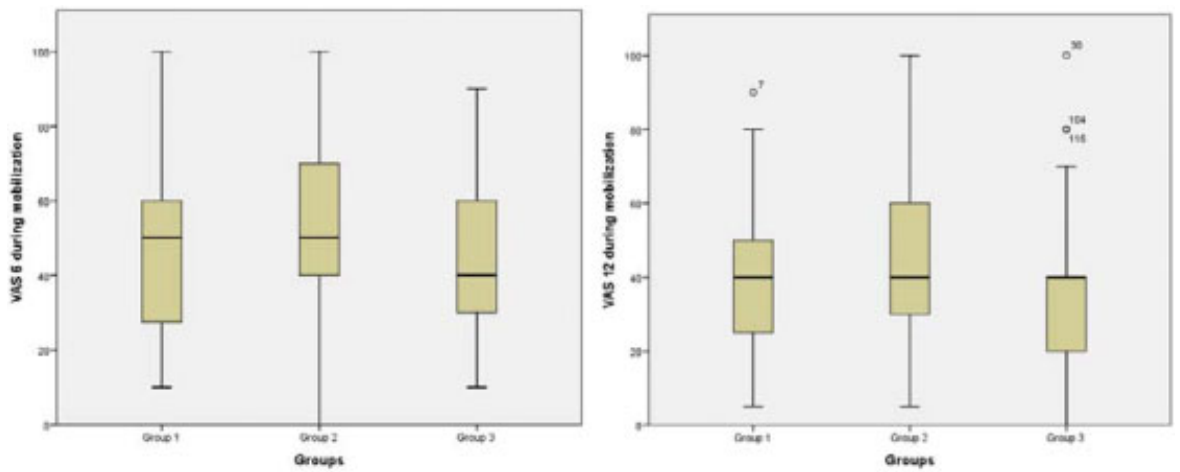

Fig. 1 Boxplot graphics of postoperative pain scores at the 6th and 12th hours during mobilization.

Table 3 Comparison of groups in terms of analgesia requirements

\begin{tabular}{lllll}
\hline & $\begin{array}{l}\text { Group 1 } \\
\mathbf{N}=60\end{array}$ & $\begin{array}{l}\text { Group 2 } \\
\mathbf{N}=60\end{array}$ & $\begin{array}{l}\text { Group 3 } \\
\mathbf{N}=60\end{array}$ & $\begin{array}{l}\text { p-values } \\
\text { (among } \\
\text { groups) }\end{array}$ \\
\hline Diclofenac & $1(0-2)^{\mathrm{a}}$ & $1(0-2)^{\mathrm{a}}$ & $1(0-4)$ & 0.043 \\
Meperidine & $1(0-1)$ & $1(0-2)$ & $1(0-1)$ & 0.177 \\
\hline
\end{tabular}

Kruskal-Wallis variance analysis as appropriate; Bold values represent

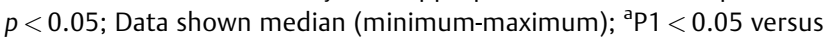
P2 (Kruskal-Wallis, Mann-Whitney U-test)
The comparison of the groups in terms of analgesia requirements is summarized in - Table 3 . The use of diclofenac was significantly different between the groups, being higher among patients in group 1. Meperidine requirements were similar in all groups. The use of diclofenac in group 1 was found higher than in group 2. The first gas and stool expulsion times for each group are summarized in - Table 4 . There was no difference between the groups' first flatus and stool passage times.

Table 4 Comparison of groups in terms of first passage of flatus and stool times

\begin{tabular}{|c|c|c|c|c|c|c|}
\hline & & $\begin{array}{l}\text { Group } 1 \\
\mathrm{~N}=60\end{array}$ & $\begin{array}{l}\text { Group } 2 \\
\mathrm{~N}=60\end{array}$ & $\begin{array}{l}\text { Group } 3 \\
\mathrm{~N}=60\end{array}$ & $\begin{array}{l}\text { p-values } \\
\text { (among groups) }\end{array}$ & \\
\hline \multirow[t]{3}{*}{ Time to first pass flatus } & & & $16(4-33)$ & $16(1-40)$ & $14.5(2-41)$ & 0.626 \\
\hline & Before $24 \mathrm{~h}$ & $47(31.8 \%)$ & $52(35.1 \%)$ & 49 (33.1\%) & 0.486 & \\
\hline & 24th hour a & ater & $13(40.6 \%)$ & $8(25.0 \%)$ & & $11(34.4 \%)$ \\
\hline \multirow[t]{3}{*}{ Time to first pass stool } & Before 24h & $8(27.6 \%)$ & $13(44.8 \%)$ & $8(27.6 \%)$ & 0.265 & \\
\hline & 24-48 hour & & $29(31.2 \%)$ & 27 (29.0\%) & & $37(39.8 \%)$ \\
\hline & 48th hour a & ater & $23(39.7 \%)$ & $20(34.5 \%)$ & & 15 (25.9\%) \\
\hline
\end{tabular}

Kruskal-Wallis and Pearson chi-Squared test; Data shown number (\%) and median (minimum-maximum).

(before pregnancy), weight gain during pregnancy, height, and BMI (before pregnancy) were not significantly different between the groups. The BMI (before birth) was significantly higher in group 2 than in groups 1 and 3.

The comparison of the groups in terms of the VAS of the subgroups is summarized in - Table 2 and - Figure 1. At the $2^{\text {nd }}$ postoperative hour, the VAS was evaluated only while lying down, whereas at the other times, it was evaluated while lying down and during mobilization. The postoperative pain scores were similar at the $2^{\text {nd }}, 6^{\text {th }}, 12^{\text {th }}$, and $18^{\text {th }}$ hours while lying down. During mobilization, the postoperative pain scores were different between the groups at the $6^{\text {th }}$ and $12^{\text {th }}$ hours, and the pain scores at the $6^{\text {th }}$ and $12^{\text {th }}$ hours were significantly higher in group 2 than in group 3.

\section{Discussion}

The frequency of cesarean section is steadily increasing all over the world, as it is in Turkey. ${ }^{1,2,11}$ The CS rate, which was $14.3 \%$ in 1993 , increased to $51.9 \%$ in 2013 in Turkey. ${ }^{12}$ There is no standard method for CS in the world. There are many procedural differences, from the opening to the closure of the skin incision. ${ }^{13-16}$ We investigated the effect of the closure types of the anterior abdominal wall layers on early postoperative findings of bowel motility in this study. Postoperative pain scores at 6 and 12 hours were significantly higher in group 2 than in group 3 during mobilization. Diclofenac use was significantly higher in patients in group 1 than in group 2. Meperidine requirements were similar between the 
groups. There was no difference between the groups in terms of first flatus and stool passage times.

When searching the literature, many studies comparing different stages of CS from skin incision to uterine closure $4,7,8,14,17$ were found. For example, Palatnik and Grob$\operatorname{man}^{18}$ found that vertical incisions did not improve maternal and fetal outcomes, and Daykan et al. ${ }^{19}$ found that skin closure using glue or a monofilament synthetic suture had similar results. With consideration to the closure of the uterus, Marceau et al. found that two-layer closure was more effective than single-layer closure. ${ }^{17}$ There are also studies suggesting that the risk of uterine dehiscence and rupture has not changed. ${ }^{20}$ In peritoneal closure, Kapustian et al. $^{7}$ found that closure of the parietal peritoneum did not change the adhesion ratio. ${ }^{7}$ However, there are some studies showing that non-closure of the peritoneum is associated with increased adhesions. ${ }^{5,21}$

There has been a long-standing hypothesis that there is a relationship between the approximation of the rectus abdominis muscle and pain, ${ }^{3,22}$ but, finally, two randomized controlled trials were recently published ${ }^{8,9}$; Lyell et al. $^{8}$ found that rectus muscle reapproximation increased immediate postoperative pain without differences in operative time, surgical complications, or maternal satisfaction, and Omran et al. ${ }^{9}$ found that rectus muscle reapproximation among women undergoing primary CS was associated with a significant increase in postoperative pain and analgesic requirements. Both studies, however, focused on rectus muscle approximation versus no approximation and did not examine its relationship with the closure and non-closure of the parietal peritoneum. In our study, closure of the abdominal wall layers was examined as three separate groups. Postoperative pain scores were found to be similar at the $2^{\text {nd }}, 6^{\text {th }}, 12^{\text {th }}$, and $18^{\text {th }}$ hours while the patients were lying down. During mobilization, postoperative pain scores were different between the groups at 6 and 12 hours. Pain scores at 6 and 12 hours were found to be significantly higher in the parietal peritoneum closure group than in the group undergoing both closure of the parietal peritoneum and reapproximation of the rectus muscle. The approximation of the rectus muscle did not increase postoperative pain and analgesia requirement.

Postoperative intestinal dysfunction is a physiologic response to abdominal surgery and is more common in open surgery, such as $\mathrm{CS}^{11}$ Gastrointestinal dysfunction may cause abdominal discomfort due to the accumulation of intestinal contents following CS and may cause a wide range of symptoms, such as nausea, vomiting, or abdominal pain. For this reason, postoperative hospital stay may be prolonged. ${ }^{2,23}$ Few studies in the literature have examined the return of intestinal motility after CS. The reason why some patients have early or late bowel motility and its relationship to surgical technique has not been investigated. Studies examining the effect of gum chewing and early oral feeding are available in the literature. ${ }^{24,25}$ The aim of this study was to investigate the effect of a tighter closure of abdominal compartment on intestinal motility after closure or nonclosure of the rectus muscle or peritoneum. We found that closure of the anterior abdominal wall had no effect on bowel motility.

This prospective cross-sectional study ensured standardization of factors that could affect postoperative pain. All women participating in our study received the same intraoperative anesthesia, followed the same postoperative pain management protocol, and underwent similar surgical techniques so as to reduce the number of potentially confounding variables. Accordingly, we excluded patients with conditions that might influence pain and bowel motility.

The limitations of this study include the follow-up of only postoperative short-term results; the long-term results of aspects such as uterine involution, adhesions, and diastasis recti were not studied. Also, the lack of questioning the patients' previous pain conditions, having no data about the duration of surgery, blood loss, and episodes of nausea and vomiting were other limitations. In addition, mobilization times that could potentially affect gastrointestinal motility could not be controlled. The strength of this study is that it is the first to investigate the effect of closure of the anterior abdominal wall on the postoperative return of bowel motility.

\section{Conclusion}

In the group with only parietal peritoneum closure, the pain scores at the 6 th and 12 th hours were higher. Rectus abdominis muscle reapproximations were found to not increase the pain score. The closure of the anterior abdominal wall had no effect on the return of bowel motility. Whether or not the anterior abdominal wall is closed has no effect on bowel motility and analgesia requirement. The studies that consider analyzing directly intraabdominal pressures, intestinal motility time, mobilization time of the patient and measuring pain scores more objectively can give more consistent results.

\section{Contributions}

All the authors contributed equally to this paper, namely to the conception and design, data collection or analysis, and interpretation of data, writing of the article, and review of the intellectual content. Therefore, all authors approved the final version to be published.

\section{Conflict of Interests}

The authors have no conflict of interests to declare.

\section{References}

1 Boerma T, Ronsmans C, Melesse DY, Barros AJD, Barros FC, Juan L, et al. Global epidemiology of use of and disparities in caesarean sections. Lancet. 2018;392(10155):1341-1348. Doi: 10.1016/ S0140-6736(18)31928-7

2 Boatin AA, Schlotheuber A, Betran AP, Moller AB, Barros AJD, Boerma $\mathrm{T}$, et al. Within country inequalities in caesarean section rates: observational study of 72 low and middle income countries. BMJ. 2018;360:k55. Doi: 10.1136/bmj.k55

3 Encarnacion B, Zlatnik MG. Cesarean delivery technique: evidence or tradition? A review of the evidence-based cesarean 
delivery. Obstet Gynecol Surv. 2012;67(08):483-494. Doi: 10.1097/OGX.0b013e318267699f

4 Popov I, Stořkov S, Bakŭrdzhiev G, Khristova P. [A single-stage 2layer suture in cesarean section-the effect of the surgical technic on postoperative febrile conditions]. Akush Ginekol (Sofiia). 1994; 33(02):13-15Bulgarian.

5 Cheong YC, Premkumar G, Metwally M, Peacock JL, Li TC. To close or not to close? A systematic review and a meta-analysis of peritoneal non-closure and adhesion formation after caesarean section. Eur J Obstet Gynecol Reprod Biol. 2009;147(01):3-8. Doi: 10.1016/j.ejogrb.2009.06.003

6 Bamigboye AA, Hofmeyr GJ. Closure versus non-closure of the peritoneum at caesarean section: short- and long-term outcomes. Cochrane Database Syst Rev. 2014;(08):CD000163. Doi: 10.1002/14651858.CD000163.pub2

7 Kapustian V, Anteby EY, Gdalevich M, Shenhav S, Lavie O, Gemer O. Effect of closure versus nonclosure of peritoneum at cesarean section on adhesions: a prospective randomized study. Am J Obstet Gynecol. 2012;206(01):56.e1-56.e4. Doi: 10.1016/j.ajog.2011.07.032

8 Lyell DJ, Naqvi M, Wong A, Urban R, Carvalho B. Rectus muscle reapproximation at cesarean delivery and postoperative pain: a randomized controlled trial. Surg J (N Y). 2017;3(03):e128-e133. Doi: $10.1055 / \mathrm{s}-0037-1604074$

9 Omran EF, Meshaal H, Hassan SM, Dieb AS, Nabil H, Saad H. The effect of rectus muscle re-approximation at cesarean delivery on pain perceived after operation: a randomized control trial. J Matern Fetal Neonatal Med. 2019;32(19):3238-3243. Doi: 10.1080/14767058.2018.1461829

10 Faul F, Erdfelder E, Lang AG, Buchner A. G*Power 3: a flexible statistical power analysis program for the social, behavioral, and biomedical sciences. Behav Res Methods. 2007;39(02):175-191. Doi: $10.3758 /$ bf03193146

11 Koc I. Increased cesarean section rates in Turkey. Eur J Contracept Reprod Health Care. 2003;8(01):1-10

12 Santas G, Santas F. Trends of caesarean section rates in Turkey. J Obstet Gynaecol. 2018;38(05):658-662. Doi: 10.1080/ 01443615.2017.1400525

13 Stegwee SI, Jordans I, van der Voet LF, van de Ven PM, Ket J, Lambalk $C B$, et al. Uterine caesarean closure techniques affect ultrasound findings and maternal outcomes: a systematic review and meta-analysis. BJOG. 2018;125(09):1097-1108. Doi: 10.1111/1471-0528.15048

14 Dodd JM, Anderson ER, Gates S, Grivell RM. Surgical techniques for uterine incision and uterine closure at the time of caesarean section. Cochrane Database Syst Rev. 2014;(07):CD004732. Doi: 10.1002/14651858.CD004732.pub3
15 AbdElaal NK, Ellakwa HE, Elhalaby AF, Shaheen AE, Aish AH. Scalpel versus diathermy skin incision in Caesarean section. J Obstet Gynaecol. 2019;39(03):340-344. Doi: 10.1080/ 01443615.2018.1527298

16 Shinde G, Pawar A, Jadhav B, Rathod K. Modified extraperitoneal Caesarean section: clinical experience. Trop Doct. 2012;42(04): 188-190. Doi: 10.1258/td.2012.120241

17 Vachon-Marceau C, Demers S, Bujold E, Roberge S, Gauthier RJ, Pasquier JC, et al. Single versus double-layer uterine closure at cesarean: impact on lower uterine segment thickness at next pregnancy. Am J Obstet Gynecol. 2017;217(01):65.e1-.e5. Doi: 10.1016/j.ajog.2017.02.042

18 Palatnik A, Grobman WA. The association of skin-incision type at cesarean with maternal and neonatal morbidity for women with multiple prior cesarean deliveries. Eur J Obstet Gynecol Reprod Biol. 2015;191:121-124. Doi: 10.1016/j.ejogrb.2015.06.009

19 Daykan Y, Sharon-Weiner M, Pasternak Y, Tzadikevitch-Geffen K, Markovitch O, Sukenik-Halevy R, et al. Skin closure at cesarean delivery, glue vs subcuticular sutures: a randomized controlled trial. Am J Obstet Gynecol. 2017;216(04):406.e1-406.e5. Doi: 10.1016/j.ajog.2017.01.009

20 Di Spiezio Sardo A, Saccone G, McCurdy R, Bujold E, Bifulco G, Berghella V. Risk of Cesarean scar defect following single- vs double-layer uterine closure: systematic review and meta-analysis of randomized controlled trials. Ultrasound Obstet Gynecol. 2017;50(05):578-583. Doi: 10.1002/uog.17401

21 Shi Z, Ma L, Yang Y, Wang H, Schreiber A, Li X, et al. Adhesion formation after previous caesarean section-a meta-analysis and systematic review. BJOG. 2011;118(04):410-422. Doi: 10.1111/ j.1471-0528.2010.02808.x

22 Dahlke JD, Mendez-Figueroa H, Rouse DJ, Berghella V, Baxter JK, Chauhan SP. Evidence-based surgery for cesarean delivery: an updated systematic review. Am J Obstet Gynecol. 2013;209(04): 294-306. Doi: 10.1016/j.ajog.2013.02.043

23 Ge W, Chen G, Ding YT. Effect of chewing gum on the postoperative recovery of gastrointestinal function. Int J Clin Exp Med. 2015;8(08):11936-11942

24 Altraigey A, Ellaithy M, Atia H, Abdelrehim W, Abbas AM, Asiri M. The effect of gum chewing on the return of bowel motility after planned cesarean delivery: a randomized controlled trial. J Matern Fetal Neonatal Med. 2020;33(10):1670-1677. Doi: $10.1080 / 14767058.2018 .1526913$

25 Huang $\mathrm{H}$, Wang $\mathrm{H}$, He M. Early oral feeding compared with delayed oral feeding after cesarean section: a meta-analysis. J Matern Fetal Neonatal Med. 2016;29(03):423-429. Doi: $10.3109 / 14767058.2014 .1002765$ 